\title{
First report of anti-TIF1 $\gamma$ dermatomyositis in a patient with myelodysplastic syndrome
}

\author{
B. Palterer ${ }^{1}$, G. Vitiello', D. Cammelli ${ }^{2}$ \\ 'Experimental and Clinical Medicine Dept., University of Florence, Florence, Italy; \\ ${ }^{2}$ Rheumatology Section/Immunoallergology Unit, AOU-Careggi, Florence, Italy
}

\begin{abstract}
SUMMARY
Inflammatory myopathies as para-neoplastic phenomena were first described by Sterz in 1916. Recently, myositis specific autoantibodies were described in cancer-associated myositis. Anti-transcription intermediary factor 1 gamma (anti-TIF1 $\gamma$ ) antibodies have been found in both young adults affected by juvenile dermatomyositis and in elderly patients with cancer-associated myositis.

In this regard, we report herein the first case of anti-TIF1 $\gamma$ dermatomyositis secondary to a myelodysplastic syndrome.
\end{abstract}

Key words: Myelodisplastic syndrome; Myositis specific autoantibodies;Anti-TIF1 $\gamma$; Dermatomyositis.

Reumatismo, 2017; 69 (2): 75-77

\section{INTRODUCTION}

nflammatory myopathies as para-neoplastic phenomena were first described by Sterz in 1916. Recently, myositis specific autoantibodies (MSA) were described in cancer-associated myositis. Anti-transcription intermediary factor 1 gamma (antiTIF1 $\gamma$ ) antibodies have been found in both young adults affected by juvenile dermatomyositis and in elderly patients with cancerassociated myositis (1).

In this regard, we report herein the first case of anti-TIF1 $\gamma$ dermatomyositis secondary to a myelodysplastic syndrome (MDS).

\section{CASE REPORT}

R.F. was a 78-year-old woman with a history of megaloblastic anemia, hypertension and osteoporosis complicated by several vertebral fractures and a mild cognitive impairment in a context of chronic vascular encephalopathy. Suddenly, she developed generalized asthenia, shoulder girdle weakness, rapidly worsening dysphagia and generalized itching rash associated with erythema of the face and palpebral edema. Antihistamines and low-dose corticosteroid therapies were not effective. She was hospitalized in our department because of inhalation pneumonia due to severe dysphagia. Physical examination revealed manual muscle testing (MMT) grade 2, heliotrope rash of the face with periorbital swelling, shawl and V-sign shaped erythematous lesions, Gottron's sign on both hands and periungual telangiectasia. Blood test examinations showed mild megaloblastic anemia (haemoglobin $10.4 \mathrm{~g} / \mathrm{dL}$, mean corpuscular volume $120 \mathrm{fL}$ ) and an erythrocyte sedimentation rate of $25 \mathrm{~mm} / \mathrm{h}$. Vitamin B12 and folic acid were within normal limits. Markers of muscular damage were within normal limits (creatine kinase $56 \mathrm{UI} / \mathrm{L}$, aldolase 7.1 UI/L). Indirect immunofluorescence on HEp-2 cells revealed high-titer speckled antinuclear antibodies. Myositis-specific and associated autoantibodies lineblot assay ("Autoimmune Inflammatory Myopathies 16 Ag", Euroimmun Medizinische Labordiagnostika AG, Lubek, DE) revealed isolated positivity of anti-TIF1 $\gamma$ antibodies (Table I). Electromyography was consistent with a myositic process involving the superior limb girdle. Total body computed tomography scan, bilateral mammography, gastroscopy and colonoscopy resulted negative for any solid tumor involvement. A total body positron emission tomography excluded the presence of hyper-
Corresponding author Gianfranco Vitiello Experimental and Clinical Medicine Department

University of Florence Azienda Ospedaliero-Universitaria Careggi Largo Brambilla, 3 50134 Florence, Italy E-mail: gianfranco.vitiello@unifi.it 
Table I - Laboratory data.

\begin{tabular}{|c|c|c|}
\hline Variable & Reference range & Value \\
\hline Hemoglobin (g/dL) & $12-16$ & 10.4 \\
\hline Mean corpuscular volume (fL) & $81-94$ & 120 \\
\hline Platelet count $\left(x 10^{9} / L\right)$ & $140-440$ & 144 \\
\hline White cell count (per mm³) & $4000-10,000$ & 4960 \\
\hline $\begin{array}{l}\text { Differential white cell count (\%) } \\
\text { Neutrophils } \\
\text { Lymphocytes } \\
\text { Monocytes } \\
\text { Eosinophils } \\
\text { Basophils }\end{array}$ & $\begin{array}{c}37-75 \\
12-50 \\
3-12 \\
0-7 \\
0-2\end{array}$ & $\begin{array}{c}60.1 \% \\
23.6 \% \\
15.1 \% \\
0.8 \% \\
0.4 \%\end{array}$ \\
\hline Creatine phosphokinase (UI/L) & $21-215$ & 56 \\
\hline Aldolase (UI/L) & $<7.4$ & 7.1 \\
\hline Aspartate transaminase (UI/L) & $15-37$ & 35 \\
\hline Alanine transaminase (UI/L) & $12-65$ & 24 \\
\hline Lactate dehydrogenase (UI/L) & $84-286$ & 319 \\
\hline Ferritin (ng/mL) & $8-252$ & 748 \\
\hline Vitamin B12 (pg/mL) & $254-1320$ & 1159 \\
\hline Folate (ng/ml) & $3.1-17.5$ & 6.3 \\
\hline Antinuclear antibodies (ANA) & $\geq 1: 160$ & $\geq 1: 640$ \\
\hline $\begin{array}{l}\text { Myositis profile } \\
\text { Anti-OJ } \\
\text { Anti-EJ } \\
\text { Anti-PL12 } \\
\text { Anti-PL7 } \\
\text { Anti-SRP } \\
\text { Anti-Mi2 } \alpha \\
\text { Anti-Mi2 } \beta \\
\text { Anti-TIF } 1 \gamma \\
\text { Anti-MDA5 } \\
\text { Anti-NXP2 } \\
\text { Anti-SAE1 }\end{array}$ & $\begin{array}{l}\text { Negative } \\
\text { Negative } \\
\text { Negative } \\
\text { Negative } \\
\text { Negative } \\
\text { Negative } \\
\text { Negative } \\
\text { Negative } \\
\text { Negative } \\
\text { Negative } \\
\text { Negative }\end{array}$ & $\begin{array}{c}\text { Negative } \\
\text { Negative } \\
\text { Negative } \\
\text { Negative } \\
\text { Negative } \\
\text { Negative } \\
\text { Negative } \\
+++ \\
\text { Negative } \\
\text { Negative } \\
\text { Negative }\end{array}$ \\
\hline
\end{tabular}

metabolic activity. Bone marrow biopsy was suggestive of myelodysplastic syndrome (refractory anemia with unilineage dysplasia according to 2008 World Health Organization classification of MDS). Fluorescent in-situ hybridization revealed a partial deletion on the long arm of chromosome 20 . The patient refused to undergo muscle biopsy and muscular magnetic resonance imaging was not performed to avoid treatment delay. However, on the basis of these findings, a diagnosis of anti-TIF1 $\gamma$ dermatomyositis secondary to MDS was made. Large spectrum antibiotic therapy was administered for inhalation pneumonia. Steroid pulse therapy with 6-methylprednisolone (1 g/daily i.v. for three days) and high-dose i.v. immunoglobulins (30 g/daily for four days) were started and methotrexate $15 \mathrm{mg} /$ weekly was added to therapy when corticosteroids were tapered. At discharge, the patient's general condition was improved, with moderately restored muscle strength (MMT 3+). However, total enteral nutrition was required due to severe dysphagia. No therapy was needed to treat the MDS because of the stability of blood count exams (2). No evidence of solid malignancy was found during the subsequent follow-up. One year later, another episode of aspiration pneumonia led the patient to death.

\section{DISCUSSION AND CONCLUSIONS}

The evidence of an association between idiopathic inflammatory myopathies and solid tumors has been known for a long time. In a case series of 618 dermatomyositis patients, 198 cases of tumor were found, among which 115 had been identified after the diagnosis of dermatomyositis (3).

A connection between haematological malignancies and inflammatory myopathies has been recently described (4). Anti-TIF1 $\gamma$ antibodies were described for the first time in 2006 as myositis specific antibodies associated with an elevated risk of malignancies. Epidemiological studies found $78 \%$ sensitivity and $89 \%$ specificity for diagnosis of cancer-associated dermatomyositis (5). TIF1 $\gamma$ is part of the TIF1 family, a group of proteins that plays a pivotal role in many cellular processes, including carcinogenesis. In fact, TIF $1 \gamma$ inhibits the TGF $\beta$ signaling through the ubiquination of SMAD4, while TIF $1 \alpha$ and TIF1 $\beta$ participate in p53 regulation processes. The increased expression of these proteins in several tumoral tissues may be associated to a misdirected immunologic anti-tumoral response. This association would explain an etiopathogenetic link between neoplasms and myositis (5-7). Autoimmune phenomena associated with myelodysplastic syndrome are well described in the literature. The most common manifestations reported are arthritis and vasculitis; other less frequent manifestations are rheumatoid arthritis, systemic lupus erythematous, Sjögren syndrome, ul- 
cerative colitis, haemolytic anemia, thrombotic thrombocytopenic purpura, relapsing polychondritis, Sweet syndrome, pyoderma gangrenosum, glomerulonephritis, polyneuropathies and autoimmune thyroiditis. Association with inflammatory myopathies has been very rarely described (8-15).

In particular, in the case report published by Tsuji et al., antinuclear antigens were found, but the assay for anti-Jo1, RNP and Scl70 resulted negative.

Our case report shows how, in the absence of proven solid tumors, focused investigations for haematological malignancies have to be considered. In addition to this, we have reported herein the first description of an anti-TIF1 $\gamma$ dermatomyositis secondary to MDS. According to the literature, DM-associated haematological malignancies have a poor prognosis. Among them, anti-TIF1 $\gamma$ dermatomyositis secondary to MDS could represent a subgroup with a particularly severe prognosis. The real contribution of anti-TIF1 $\gamma$ antibodies secondary to hematopoietic malignancies has not been fully established, and their role in the pathogenesis of both hematologic disorders, such as MDS, and cancer-induced myositis has still not been established.

Contributions: $\mathrm{BP}$ and $\mathrm{GV}$ contributed equally to this work. BP, GV, DC manuscript writing; BP, GV reference search and manuscript editing; DC manuscript reviewing.

\section{Funding: none}

\section{Conflict of interest: none}

\section{REFERENCES}

1. Shah AA, Casciola-Rosen L, Rosen A. Review: cancer-induced autoimmunity in the rheumatic diseases. Arthritis Rheumatol. 2015; 67: 317-26.

2. Braun T, de Botton S, Taksin AL, et al. Characteristics and outcome of myelodysplastic syndromes (MDS) with isolated 20q deletion: a report on 62 cases. Leuk Res. 2011; 35: 863-7.

3. Hill CL, Zhang Y, Sigurgeirsson B, et al. Fre- quency of specific cancer types in dermatomyositis and polymyositis : a population-based study. Lancet. 2001; 357: 96-100.

4. Marie I, Guillevin L, Menard JF, et al. Hematological malignancy associated with polymyositis and dermatomyositis. Autoimmun Rev. 2012; 11: 615-20.

5. Trallero-Araguás E, Rodrigo-Pendás JÁ, SelvaO'Callaghan A, et al. Usefulness of anti-p155 autoantibody for diagnosing cancer-associated dermatomyositis: a systematic review and meta-analysis. Arthritis Rheum. 2012; 64: 523-32.

6. Kaji K, Fujimoto M, Hasegawa M, et al. Identification of a novel autoantibody reactive with 155 and $140 \mathrm{kDa}$ nuclear proteins in patients with dermatomyositis : an association with malignancy. Rheumatology (Oxford). 2007; 46: 25-8.

7. Fujimoto M, Hamaguchi Y, Kaji K, et al. Myositis-specific anti-155/140 autoantibodies target transcription intermediary factor 1 family proteins. Arthritis Rheum. 2012; 64: 513-22.

8. Ustwani O Al, Ford LA, Sait SJN, et al. Myelodysplastic syndromes and autoimmune diseases - case series and review of literature. Leuk Res. 2013; 37: 894-9.

9. Mekinian A, Grignano E, Braun T, et al. Systemic inflammatory and autoimmune manifestations associated with myelodysplastic syndromes and chronic myelomonocytic leukaemia: a French multicentre retrospective study. Rheumatology (Oxford). 2015; 55: 291-300.

10. Tsuji G, Maekawa S, Saigo K, et al. Dermatomyositis and myelodysplastic syndrome with myelofibrosis responding to methotrexate therapy. Am J Hematol. 2003; 178: 175-8.

11. Enright H, Jacob H, Vercellotti G, et al. Paraneoplastic autoimmune phenomena in patients with myelodysplastic syndromes: response to immunosuppressive therapy. $\mathrm{Br} \mathrm{J}$ Haematol. 1995; 91: 403-8.

12. Mayeda Y, Arakawa K, Araki E, et al. [Polymyositis and cutaneous vasculitis in a patient with myelodysplastic syndrome]. Rinsho Shinkeigaku. 1999; 39: 639-42.

13. Asman A, Ehrenfeld M, Sadeh M, et al. Polymyositis and myelodysplastic syndrome. J Rheumatol. 1991; 18: 1272-4.

14. Kanbayashi T, Masuyama A, Yokoe I, et al. [A case of myelodysplastic syndrome associated with dermatomyositis, accompanying intractable gastrointestinal bleeding due to cytomegalovirus gastroenteritis]. Rinsho Riumachi. 2012; 24: 81-6

15. Nakanishi T, Horikoshi H, Kusanagi Y, et al. Refractory dermatomyositis complicated with myelodysplastic syndrome. Internal Medicine. 2015; 54: 2507-11. 